\title{
Choice to Take Advanced Placement Course(s) in Preparing Students for STEM Majors: The role of Identification with Academics and School Motivation
}

\author{
Weihua Fan, Yali Zou, Jennifer Bahrman \\ University of Houston, USA
}

\begin{abstract}
Applying the expectancy-value theory, the present study examined how motivational factors (including self-efficacy, utility value, and interest in math and science respectively) and identification with academics (math and science identify respectively) predict whether students plan to take AP calculus and science courses while controlling for student's social-economic status and achievement. The study utilized a nationally representative dataset from the High School Longitudinal Study of 2009 (HSLS:09), which surveyed more than 21,000 9th American students in 944 schools. The study expanded the extant research by showing possible pathways that motivate students to take advanced AP courses in preparing students for STEM majors. The pathway is specifically rooted in students' domain-specific ability belief, intrinsic interest and utility value in learning through their relationships with students'. The results of the study convey significant practical implications to educators seeking to improve students' enrollment in advanced AP math and science courses.
\end{abstract}

\section{Introduction}

The fields of science, technology, engineering, and math, commonly referred to as STEM, are an integral domain of the United States infrastructure and have fueled economic growth in the US over the past decades. It has been increasingly recognized in the recent decades that US high school students are underprepared to choose and complete STEM majors in colleges, which leads to a major shortage of domestic students taking careers such as science and engineers. Recent results indicate that fewer than half of all high school seniors met college readiness benchmarks for math and science [1] and do not possess the essential fundamental skills in math and science to succeed in post-secondary STEM education and careers [2]. These solemn statistics demonstrate the critical need for offering more advanced classes in high school to prepare American students for STEM education and careers in order to boost the number of students entering post-secondary education and graduating as scientists, mathematicians, and engineers and strengthening the US' competitive role internationally.

National policy recommendations suggest that one approach to remediate this deficit is enlarging the pool of students pursuing degrees and careers in STEM fields by increasing the number of students taking Advanced Placement (AP) courses during high school [3], [9]. Policy recommendations would thereby target offering more opportunities for students to become prepared for engaging in future STEM careers. Research has vastly demonstrated that enrollment in AP classes is a significant predictor of a student's graduation from college [4] and research has provided support that increasing students' enrollment in AP classes results in greater STEM career interest [16] and accomplishments [19] as it offers educational opportunities designed to be intellectually challenging and rigorous.

Although efforts are in place in rectifying the lack of preparation of US students for STEM fields, less focus has been given to the motivation of students to prepare for post-secondary STEM disciplines. A good deal of evidence has indicated that students' motivation plays an important role in student academic success. Existing research has suggested that math and science interest greatly shapes students' decision to pursue STEM fields [13] and that the majority of students who chose STEM careers make that choice during high school due to a growing interest rather than achievement [14]. Intent to pursue STEM disciplines of post-secondary education has also been found to be significantly and positively influenced by math self-efficacy beliefs in that students with greater self-efficacy beliefs are more likely to intend to pursue a STEM major upon college entrance [17]. However, research on how motivational factors and identification with academics may help prepare students for STEM majors is limited. 


\section{Advanced Placement Course}

Originally developed in 1955, the Advanced Placement (AP) program was established to provide students with the opportunity to take college-level coursework and earn college credit while still in high school [8]. AP coursework was never intended to be used as admission criteria, but by the 1980's began being more increasingly as an admissions component as a means of determining distinctions in how well and to what extent applicants took advantage of academic challenges and the quality of a student's education [8]. Today, AP courses are a common admissions criterion. They are so common that according to the College Board, which operates the program, the total number of students taking AP exams increased 660 percent between 1980 and 2004, and the total number of AP exams taken increased 750 percent during the same period.

The success of AP classes has been well supported in the literature in terms of early college success and graduation rates. For example, [18] found that AP students had higher first semester college GPAs than students who were not enrolled in AP courses. And a 2005 study by Dougherty, Mellor, and Jian of the National Center for Educational Accountability found that AP course enrollment has a strong relationship to college graduate rates [4]. They found that passing AP exams increased probability of college graduation by 28-33 percent and that even enrollment alone, without taking AP exams, resulted in a 10-20 percent increase in college graduation probability. However, no research to date has examined in what majors AP graduates have specifically excelled in during college. Further research needs to address whether enrollment in AP math and science courses is related to college major selection.

\subsection{Motivation and STEM}

Existing research suggests that math and science interest greatly shapes students' decision to pursue STEM fields [10], [15] and that the majority of students who chose STEM careers make that choice during high school due to a growing interest rather than achievement [14]. Intent to pursue STEM disciplines of post-secondary education has also been found to be significantly and positively influenced by math self-efficacy beliefs in that students with greater self-efficacy beliefs are more likely to intend to pursue a STEM major upon college [17]. Other motivational factors, such as outcome, expectation has also been found to be linked to students' pursuit of STEM disciplines during post-secondary education in that outcome expectations show a positive and significant effect on the entrance to STEM fields [20]. This suggests that although there is evidence to support that motivation may impact students exiting secondary education with the strengths, abilities, and skill set to pursue STEM disciplines in post-secondary education and STEM careers, the depth of this research is still in infancy.

\section{Objectives}

Eccles and colleagues [5] proposed the expectancy-value model of achievement choice by providing a comprehensive framework for understanding adolescents' academic experiences, values and beliefs, and achievement-related behavior. This model states that students' perceived academic competence (i.e., ability belief) and subjective task value including students' interest in learning (i.e., intrinsic value) and student's perceived importance of the subject (i.e., utility value) play important roles in shaping their achievement-related choices and behaviors.

Applying the expectancy-value theory, the goal of the present study is to examine how motivational factors (including self-efficacy, utility value, and interest in math and science respectively) and identification with academics (math and science identify respectively) predict whether students plan to take AP calculus and science courses while controlling for student's social-economic status and achievement. Figure 1 depicts the conceptual model of the study.

\section{Method}

\subsection{Data}

The study utilized a nationally representative dataset from the High School Longitudinal Study of 2009 (HSLS:09), which surveyed more than 21,000 9th graders in 944 schools to understand students' trajectories from the beginning of high school into postsecondary education, the workforce, and beyond. Our study focused on a nationally representative sample of 21444 adolescents, among which $49.2 \%$ were female, and $50.8 \%$ were male; $55.3 \%$ were White students, $15.4 \%$ were Hispanic students, $10.3 \%$ were African-American students, 7.8\% were Asian students, and the rest was other race(s).

\subsection{Measures}

Measures of the domain specific subscales of student beliefs and opinions regarding identification with academics, academic self-efficacy, intrinsic motivation, and utility value in the HSLS: 09 datasets were used for the analyses. These scales were adopted and adjusted from existing surveys in the literature such as the Motivated Strategies for Learning Questionnaire [13] and the self-report 
Scale of Intrinsic Versus Extrinsic Orientation [11]. Identification with academics was assessed by two items on a 4-point Likert scale including "you see yourself as a math/science person" and "others see you as a math/science person". Since research has provided strong empirical support for the domain specificity of motivational constructs (e.g., [6], [7]), all the motivational constructs were assessed for math and Science respectively in the present study with acceptable Cronbach reliability at or above .65 . Students' plan to enroll in Advanced Placement (AP) calculus course or science course was assessed with one single item respectively asking students to report whether or the student plans to take the course (Yes-1 and No-0). In addition, control variables assessing students' socio-economic status (SES) and prior math achievement were also included in the study. All measures were assessed in 2009 when students were in 9 th grade.

\subsection{Plan of Analysis}

A path analysis approach was used to examine how student domain-specific motivation (selfefficacy in math and science, intrinsic motivation in math and science, utility value in math and science) and domain identity predict whether students plan to take AP calculus or science course while controlling for student's social-economic status and achievement. The following criteria were used to assess model-data fit. CFI greater than .95, SRMR below .08, and RMSEA less than or equal to .06 indicate strong model data fit, and CFI close to .90, SRMR close to .10 and RMSEA close to .08 indicate acceptable model data fit [12]. The analyses were conducted using Mplus.

\section{Results}

Table 1 presents the correlations among all the motivational variables and outcomes examined in the present study. All the correlations were significant at .01 level. Among all the motiviational variables, students' math identity had the strongest correlation with their plan to take an AP math course $(r=.257, p<.01)$ and students' science identity had the strongest correlation with their plan to take an AP science course $(r=.349, p<.01)$. In addition, students' math identity significantly correlated with all other motivational variables, with highest coefficients with math self-efficacy $(r=.439, p<$. $01)$ and math intrinsic motivation $(r=.386, p<.01)$. Students' science identity significantly correlated with all other motivational variables, with highest coefficients with sicence self-efficacy $(r=.428, p<$. $01)$, sicence intrinsic motivation $(r=.428, p<.01)$ and sicence utility value $(r=.352, p<.01)$.
The results of path analysis showed that the model fit the data well with CFI of .974, TLI of .963, and RMESA value less than .028. As a result, the parameter estimates of the models were interpretable. The significant unstandardized parameter estimates of the model are reported in Figure 1. The findings of the present study demonstrated that students' domain-specific self-efficacy and intrinsic motivation significantly predicted their identification with academics in math and science respectively. Students' utility value in science also significantly predicted their science identity. On the contrary, students' utility value in math was not a significant predictor their math identity. In turn, students' math identity significantly predicted their plans to enroll in an AP calculus course and students' science identity significantly predicted their plans to enroll in an AP science course (see Figure 1). Interestingly, the path coefficient from students' science identity to their plan of taking an AP science course was much stronger compared to the path coefficient from students' math identity to their plan of taking an AP math course. Also, SES appeared to be a significant controlling variable for students' plans to take an AP course both in calculus and science. Prior math achievement also appeared to be a significant controlling variable for students' plan to take an AP calculus course, but not an AP science course.

\section{Discussions and Conclusions}

The present study extends the literature examining how students' motivation may play a role in their decision to take AP courses. Findings suggest that explanations for students' choice of taking advanced AP courses that rely solely on students' social background and academic behaviors without considering their motivational beliefs and attitudes are incomplete. The study expands the extant research by showing possible pathways that motivate students to take advanced AP courses. The pathway is specifically rooted in students' domainspecific ability belief, intrinsic interest and utility value in learning through their relationships with students' identification with academics. when students are genuinely interested in the tasks involved in learning math and science, confident about their abilities in in learning math and science, or perceive importance of science they tend to identify themselves with the respective subject and thus become more likely to take AP math or science course. The results of the study convey significant practical implications to educators seeking to improve students' enrollment in advanced math and science courses. A unique contribution of the present study stems from its empirical support for the conclusion that students' domain identity in math and science significantly predicted their plans 
to enroll in AP calculus or science course. The study adds to the literature by providing evidence that domain identity had a stronger path coefficient compared to other motivational constructs.

Table 1. Correlation among variables

\begin{tabular}{lllllllllll}
\hline \multicolumn{1}{c}{ Variable } & 1 & 2 & 3 & 4 & 5 & 6 & 7 & 8 & 9 & 10 \\
\hline 1. Math self-efficacy & - & & & & & & & & & \\
2. Math intrinsic motivation & .385 & - & & & & & & & & \\
3. Math utility value & .278 & .300 & - & & & & & & & \\
4. Math identity & .439 & .386 & .222 & - & & & & & & \\
5. Science self-efficacy & .360 & .170 & .193 & .243 & - & & & & & \\
6. Science intrinsic motivation & .164 & .192 & .178 & .134 & .414 & - & & & & \\
7. Science utility value & .198 & .193 & .351 & .161 & .324 & .393 & - & & & \\
8. Science identity & .198 & .126 & .132 & .202 & .428 & .428 & .352 & - & & \\
9. Plan to take AP calculus course & .241 & .189 & .132 & .257 & .226 & .139 & .138 & .209 & - & \\
10. Plan to take AP science course & .160 & .077 & .095 & .148 & .298 & .250 & .213 & .349 & .576 & - \\
\hline
\end{tabular}

Notes. All correlation coefficients are significant at 01 level.

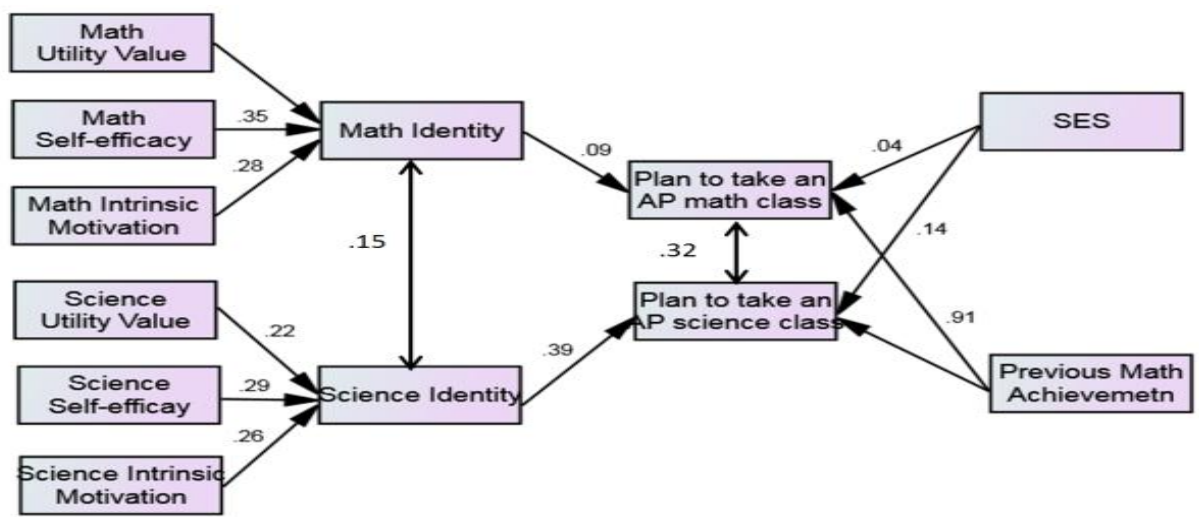

Note. All presented paths are significant at .05 level.

Figure 1. Hypothesized model

\section{References}

[1] ACT. (2013). The condition of college and career readiness. Iowa City, IA: Author.

[2] Business Higher Education Forum (2011). Meeting the STEM workforce challenge: Leveraging higher education's untapped potential to prepare tomorrow's STEMM workforce. Washington, DC: Author.

[3] Chen, X., \& Weko, T., (2009). Students who study science, technology, engineering, and mathematics (STEM) in postsecondary education (NCES 2009-161). Washington, DC: National Center for Education Statistics, U.S. Department of Education.

[4] Dougherty, C., Mellor, L., \& Jian, S., (2006). The relationship between Advanced Placement and college graduation. 2005 AP study series, Report 1. National Center for Educational Accountability.
[5] Eccles J. S., Adler, T. F., Futterman, R., Goff, S. B., Kaczala, C. M., Meece, J. L., \& Midgley, C., (1983). Expectancies, values, and academic behaviors. In J. T. Spence (Ed.), Achievement and achievement motivation (pp. 75-146). San Francisco, CA: W. H. Freeman.

[6] Fan, W., (2011). Social influences, school motivation and gender differences: An application of the expectancyvalue theory. Educational Psychology, 31(2), 157-175.

[7] Fan, W., \& Wolters, C., (2014). School motivation and high school dropout: The mediating role of educational expectation. British Journal of Educational Psychology. 84(1), 22-39.

[8] Geiser, S., \& Santelices, V., (2004). The role of advanced placement and honors courses in college admissions. Expanding opportunity in higher education: Leveraging promise, 75-113. 
[9] Government Accountability Office (GAO). (2006). Science, Technology, Engineering, and Mathematics Trends and the Role of Federal Programs (GAO-06-702T). Washington, DC: Author.

[10] Halpern, D. F., Benbow, C. P., Geary, D. C., Gur, R. C., Hyde, J. S., \& Gernsbacher, M. A., (2007). The science of sex differences in science and mathematics. Psychological science in the public interest, 8(1), 1-51.

[11] Harter, S., (1981). A new self-report scale of intrinsic versus extrinsic orientation: Motivation and informational components. Developmental Psychology, 17, 300-312.

[12] Hu, L., \& Bentler, P. M., (1999). Cutoff criteria for fit indexes in covariance structure analysis: Conventional criteria versus new alternatives. Structural Equation Modeling, 6, 1-55.

[13] Pintrich, P., Smith, D., Garcia, T., \& McKeachie, W., (1993). Predictive validity and reliability of the Motivated Strategies for Learning Questionnaire (MSLQ). Educational and Psychological Measurement, 53, 801-813.

[14] Maltese, A. V., \& Tai, R. H., (2011). Pipeline persistence: Examining the association of educational experiences with earned degrees in STEM among US students. Science Education, 95(5), 877-907.

[15] Marsh, H. W., Trautwein, U., Lüdtke, O., Köller, O., \& Baumert, J., (2005). Academic self-concept, interest, grades, and standardized test scores: Reciprocal effects models of causal ordering. Child development, 76(2), $397-$ 416.

[16] Sadler, P. M., Sonnert, G., Hazari, Z., \& Tai, R., (2014). The Role of Advanced High School Coursework in Increasing STEM Career Interest. Science Educator, 23(1), 1-13.

[17] Scott, A. B., \& Mallinckrodt, B., (2005). Parental emotional support, science self-efficacy, and choice of science major in undergraduate women. The Career Development Quarterly, 53(3), 263-273.

[18] Scott, T. P., Tolson, H., \& Lee, Y. H., (2010). Assessment of Advanced Placement Participation and University Academic Success in the First Semester: Controlling for Selected High School Academic Abilities. Journal of College Admission, 208, 26-30.

[19] Wai, J., Lubinski, D., Benbow, C. P., \& Steiger, J. H., (2010). Accomplishment in science, technology, engineering, and mathematics (STEM) and its relation to STEM educational dose: A 25-year longitudinal study. Journal of Educational Psychology, 102(4), 860.

[20] Wang, X., (2012). Modeling Student Choice of STEM Fields of Study: Testing a Conceptual Framework of Motivation, High School Learning, and Postsecondary Context of Support. WISCAPE Working Paper. Wisconsin Center for the Advancement of Postsecondary Education (NJ1). 